Thongboonkerd V (ed): Proteomics in Nephrology - Towards Clinical Applications.

Contrib Nephrol. Basel, Karger, 2008, vol 160, pp 65-75

\title{
Proteomics and Renal Transplantation: Searching for Novel Biomarkers and Therapeutic Targets
}

\author{
Stefan Schaub ${ }^{\mathrm{a}}$, John A. Wilkins ${ }^{\mathrm{b}}$, Peter Nickerson ${ }^{\mathrm{b}}$ \\ aDepartment for Transplantation Immunology and Nephrology, University Hospital \\ Basel, Basel, Switzerland; 'bections of Biomedical Proteomic and Rheumatology, \\ Manitoba Centre for Proteomics and Systems Biology, Faculty of Medicine, \\ University of Manitoba, Winnipeg, Man., Canada
}

\begin{abstract}
Renal transplantation has emerged as the preferred option for many patients with endstage renal failure. While significant progress has been achieved in short-term outcomes, long-term survival has only marginally improved. Adaptation of immunosuppressive drugs to the individual needs of every patient at every time point after transplant will be essential to improve long-term outcomes. Thus, assays are required that detect allograft injury very early, which implies frequent noninvasive measurements (e.g. in urine or serum). In this review, we describe important general aspects in urine biomarker discovery using proteomics and discuss currently published studies. Although proteomics has the potential to provide insights into complex pathophysiological processes and reveal novel diagnostic biomarkers as well as therapeutic drug targets, the actual status of urine proteomic activities in renal transplantation is still far from reaching these ambitious goals.
\end{abstract}

Copyright $@ 2008$ S. Karger AG, Basel

\section{Current Problems in Renal Transplantation}

Although short-term renal allograft survival has continuously improved over the last two decades and acute clinical rejection episodes have been significantly reduced, long-term outcome became only marginally better $[1,2]$. There are several possible interpretations for this contradictory finding. First, due to the growing gap between the increasing number of patients waiting for a deceased donor organ and the decreasing availability of organs with excellent quality, more marginal donors with pre-existing kidney pathologies have been used in recent years 


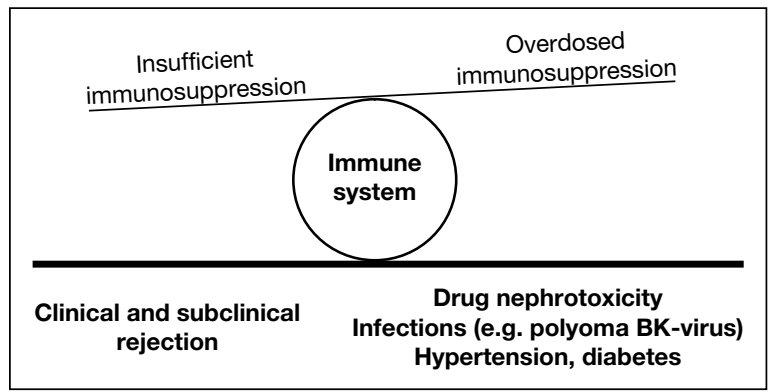

Fig. 1. Balancing the immunosuppression is a key element for successful transplantation.

(i.e. expanded criteria donors). Such organs can provide comparable survival rates in the short-term, but their inferior mass of functional kidney tissue may limit longevity. Second, the benefit of fewer clinical rejection episodes may be partially off-set by side effects of more potent immunosuppression (e.g. drug nephrotoxicity, polyoma BK virus nephropathy). Third, there is still a significant proportion of patients who have undetected subclinical rejection which damages the allograft over years. Therefore, adjusting the level of immunosuppression to the individual patient in order to balance the risk for rejection and overimmunosuppression is essential to improve long-term allograft survival (fig. 1).

Clearly, the major goal in transplantation is to reduce injuries to the allograft. While pre-existing organ damage cannot be influenced, all other insults should be limited. The effects of these insults (i.e. ischemia-reperfusion, rejection, drug-induced nephrotoxicity, infections and hypertension) accumulate over time and lead to progressive destruction of the allograft (fig. 2) [3, 4]. Several studies have shown that even subtle injuries detectable only by protocol allograft biopsies are a risk factor for subsequent deterioration of allograft function and graft loss $[5,6]$. Indeed, repeated protocol allograft biopsies would be advisable for patient management and adaptation of the immunosuppressive therapy. However, this strategy is hampered by the small but inherent risk of allograft biopsies (e.g. bleeding, arteriovenous fistula, and infection), the associated costs, and the inconvenience for patients. Therefore, noninvasive biomarkers that allow for early detection of allograft injury and correlate with allograft histology would be helpful.

\section{Diagnostic Requirements to Improve Patient Management}

Currently, noninvasive monitoring of renal allograft relies mainly on measurement of serum creatinine. However, several studies have demonstrated that 


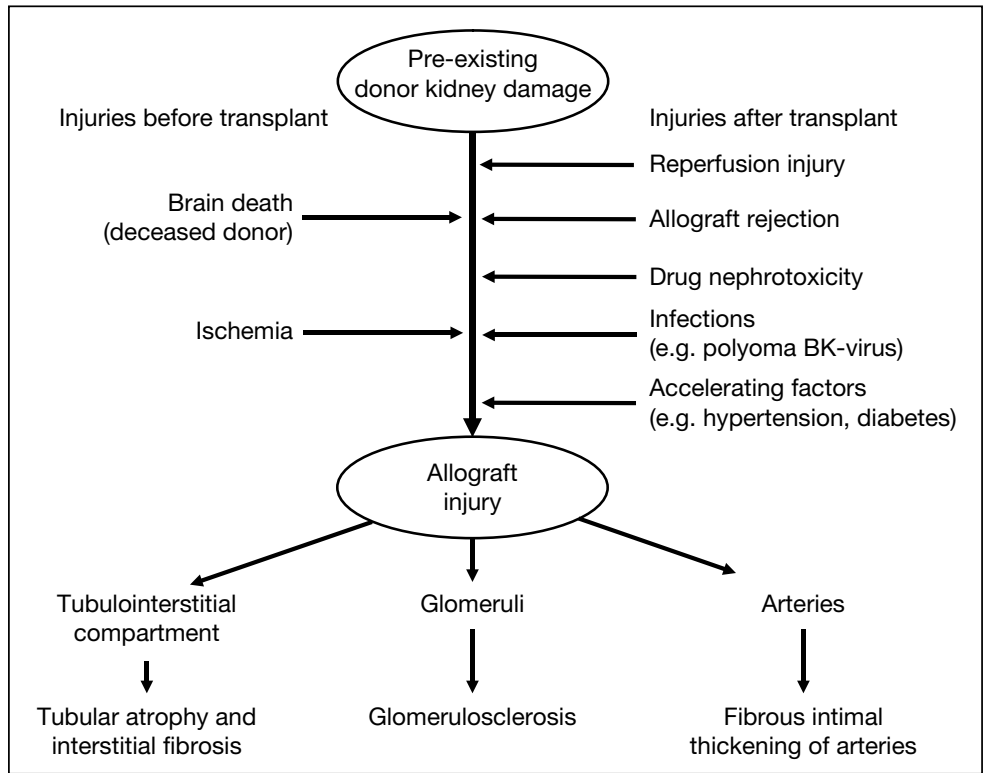

Fig. 2. Overview of factors that can lead to allograft injury. These injuries can be restricted to mainly one compartment of the allograft or can affect all compartments (i.e. tubulointerstitial compartment, glomeruli, arteries). Independent of the disease causing the injury, the final common consequence is tubular atrophy, interstitial fibrosis, glomerulosclerosis and fibrous intimal thickening of arteries, which all represent irreversible damage.

serum creatinine is not sensitive enough to detect clinically important allograft pathologies which can progress to irreversible allograft damage $[5,6]$. Therefore, assays are required that detect allograft pathologies before organ damage is severe enough to impact serum creatinine.

As detailed in figure 2, various insults (e.g. rejection, drug toxicity) can injure the allograft. In addition, these insults can affect one or more compartments of the allograft (e.g. tubulointerstitial compartment, glomeruli, arteries). For example, renal allograft rejection can present as tubulointerstitial inflammation (i.e. cellular rejection Banff Ia [7]) or can be restricted to glomeruli and arteries (i.e. antibody-mediated rejection [7]). Calcineurin inhibitors can lead to damage of small vessels or the tubulointerstitial compartment. Independent of the underlying process, the common consequence of the injury is development of irreversible tubular atrophy, interstitial fibrosis, glomerulosclerosis, and fibrous intimal thickening of arteries. 
In general, noninvasive biomarkers can be used to monitor the immune response, to assess tissue injury in the three compartments of the renal allograft, or to monitor specific diseases (e.g. polyoma BK virus nephropathy). While immune and injury monitoring have their specific limitations, combining both may enhance the accuracy of noninvasive monitoring [8].

\section{Concept of an Unbiased Proteomics-Based Approach to Develop Novel Biomarkers in Renal Transplantation}

Although many noninvasive biomarkers for renal allograft rejection have been proposed, none has found wide clinical application [8]. This highlights that the search for biomarkers enhancing noninvasive monitoring beyond serum creatinine is a difficult task [9]. With the continuously improving proteomic technology, it becomes possible to screen for novel biomarkers in an unbiased way on a broad protein level.

An unbiased proteomics-based approach to develop noninvasive biomarkers involves four steps: (a) establishment of a reproducible technological platform for analysis and determination of sample-related confounders, (b) biomarker discovery phase using well-defined clinical phenotypes, (c) biomarker validation in a strictly independent sample set, and (d) high-throughput assay development.

The first step also involves the decision as to which source (i.e. allograft tissue, serum, urine) for biomarker development will be used. Clearly, allograft tissue offers the potential to analyze the proteins of all cells involved in the investigated process and is therefore an ideal source for biomarker discovery. However, comparative analysis may be complicated by differences in the cellular composition of individual biopsies (e.g. percentage of cortex and medulla) which do not necessarily reflect the process. The use of laser-capture microdissection to select distinct compartments (e.g. glomeruli, tubules, vessels) can circumvent this confounding factor. Once a potential biomarker has been detected and identified in the tissue, it has to be measurable in urine or serum, and these levels have to correlate with the concentrations in the tissue in order to become a useful noninvasive biomarker. Serum and urine as sources for biomarker development have the advantage that collection of sufficient material is not a major issue. However, proteomic analysis in serum is hampered by its complexity. Ten high-abundance proteins (e.g. albumin, immunoglobulins) account for $>95 \%$ of the total protein content [10]. These proteins, which are unlikely to provide any useful information regarding the allograft, must be removed to allow detection of the remaining lower-abundance proteins. Urine as a specimen for proteomic analysis may offer some potential 
advantages because (a) it is in direct contact with main targets of rejection and other harmful processes (i.e. tubular epithelial cells) and (b) it may represent the whole kidney allograft. However, urine has variable and changing physicochemical properties (dilution, $\mathrm{pH}$ ) and cellular components (epithelial cells, leukocytes, red blood cells), which can affect its protein content [11]. Furthermore, stability of proteins under these changing conditions may be impaired [12].

As biomarker discovery is often performed with few samples, it is essential that these samples are carefully selected and that they represent a distinct and clinically important phenotype, and include equally well-defined control groups to enhance the significance of the detected biomarkers. In the biomarker validation step, a larger but clearly independent sample set should be used. If known biomarkers for the investigated disease/process already exist, they should be analyzed in parallel to determine the diagnostic value of the novel biomarker in comparison with existing biomarkers. Most efforts are currently concentrated in the biomarker discovery phase; however, the validation phase is critical and only few potential biomarkers have undergone this step.

\section{Current Status of Proteomic Studies in Renal Transplantation}

\section{General Aspects}

Currently published proteomic investigations in human renal transplantation are limited to studies aiming to detect novel urine biomarkers for specific pathologies (i.e. allograft rejection, polyoma BK virus nephropathy) [13-17]. Urine might be a valuable source for biomarker development of processes primarily affecting the tubulointerstitial compartment (e.g. tubulointerstitial rejection, polyoma BK virus nephropathy, drug toxicity), because urine is the only biological fluid that is in direct contact with tubular epithelial cells. In addition, urine may reflect the whole allograft overcoming the inherent limitation of allograft biopsies to miss focal processes due to sampling error [18, 19]. Indeed, urine protein analysis might be of particular interest to screen for early and subtle processes targeting the tubulointerstitial compartment.

Although there are several different proteomic platforms, high-throughput technologies such as surface-enhanced laser desorption/ionization time-offlight mass spectrometry (SELDI-TOF MS) $[13-15,17]$ and capillary electrophoresis coupled to mass spectrometry (CE-MS) [16] were used in all currently published studies searching for novel urine biomarkers in renal transplantation. Therefore, in the following paragraphs these two platforms will be described and discussed in more detail, while referring to recently published 
reviews regarding advantages and limitations of other proteomic approaches $[20,21]$.

SELDI-TOF MS combines matrix-assisted laser desorption/ionization time-of-flight mass spectrometry (MALDI-TOF-MS) with surface retentate chromatography. Specifically, a sample is applied to a chip surface carrying a functional group (e.g. normal phase, hydrophobic, cation or anion exchange). After incubation, proteins that do not bind to the surface are removed by a simple wash step, and bound peptides/proteins are analyzed by mass spectrometry. This approach reduces the complexity of the sample being analyzed by selecting only a subset of the total proteins. Spectra of samples from different groups (e.g. acute rejection vs. no rejection) can now be analyzed for differences in their respective proteomes. The advantages of SELDI-TOF MS are its user friendliness and high-throughput capabilities [11]. The major disadvantages are a limited sensitivity to detect proteins and a low resolution and mass accuracy of the generated spectra $[8,22]$. Therefore, only a restricted part of the proteome is accessible for analysis by SELDI-TOF MS.

CE-MS combines protein separation by electrophoresis coupled to an electrospray source for on-line mass spectrometric analysis. This platform provides fast analysis with high resolution and good mass accuracy of peptides/proteins smaller than $10 \mathrm{kDa}$. Limitations of CE-MS are the restriction of the investigation to small proteins and a limited sensitivity to detect proteins because only a small sample volume can be injected into the capillary. Both SELDI-TOF-MS and CE-MS were criticized because most detected potential biomarkers were not identified. Notably, the generated peptide/protein pattern analyzed with sophisticated bioinformatics can be used itself as a diagnostic assay (protein pattern diagnostic), or significantly different expressed proteins can be identified, which allows to develop quantitative, high-throughput assays (i.e. ELISA). It is unknown at this point which approach (protein pattern diagnostics or protein identification/ELISA assay development) will reveal more robust diagnostic markers that can be utilized in a clinical setting [23, 24].

\section{Published Studies Using Proteomics in Human Transplantation}

Table 1 summarizes all studies published until January 2007. Four research groups aimed to detect urine proteins associated with renal allograft rejection (in most cases tubulointerstitial rejection), one group investigated urine proteins associated with polyoma BK virus nephropathy. Although these are two different pathological processes, both lead to injury in the tubulointerstitial compartment with a subsequent tissue response, which might be a common feature. Interestingly, each group found a different set of urinary proteins that are associated with the investigated process. To understand these apparent discrepancies, one must consider that in each study disease definition, sample collection, 


\begin{tabular}{|c|c|c|c|c|c|c|c|}
\hline Reference & $\begin{array}{l}\text { Proteomic } \\
\text { platform }\end{array}$ & $\begin{array}{l}\text { Discovery of } \\
\text { bio-markers } \\
\text { for }\end{array}$ & $\begin{array}{l}\text { Use of bio- } \\
\text { informatics }\end{array}$ & $\begin{array}{l}\text { Peptides/proteins } \\
\text { detected }\end{array}$ & $\begin{array}{l}\text { Biomarker } \\
\text { identified }\end{array}$ & $\begin{array}{l}\text { Independent } \\
\text { validation } \\
\text { performed }\end{array}$ & $\begin{array}{l}\text { Validation } \\
\text { outcome }\end{array}$ \\
\hline $\begin{array}{l}\text { Clarke } \\
\text { et al. [13] }\end{array}$ & $\begin{array}{l}\text { SELDI-TOF } \\
\text { MS }\end{array}$ & $\begin{array}{l}\text { Allograft } \\
\text { rejection }\end{array}$ & Yes & $\begin{array}{l}6,500,6,600,6,700 \\
7,100,13,400 \mathrm{Da}\end{array}$ & No & No & \\
\hline $\begin{array}{l}\text { Schaub } \\
\text { et al. } \\
{[14,22,25]}\end{array}$ & $\begin{array}{l}\text { SELDI-TOF } \\
\text { MS }\end{array}$ & $\begin{array}{l}\text { Allograft } \\
\text { rejection }\end{array}$ & No & $\begin{array}{l}\text { Three peak clusters at } \\
5,270-5,550,7,050- \\
7,360 \text {, and } 10,530- \\
11,100 \mathrm{Da}\end{array}$ & $\begin{array}{l}\text { Cleaved } \beta_{2^{-}} \\
\text {microglobulin }\end{array}$ & Yes & $\begin{array}{l}\text { Biomarker is } \\
\text { confounded by } \\
\text { urine pH } \\
\text { Not specific for } \\
\text { rejection } \\
\text { Similar performance } \\
\text { as other tubular injury } \\
\text { biomarkers }\end{array}$ \\
\hline $\begin{array}{l}\text { O'Riordan } \\
\text { et al. } \\
{[15,26]}\end{array}$ & $\begin{array}{l}\text { SELDI-TOF } \\
\text { MS }\end{array}$ & $\begin{array}{l}\text { Allograft } \\
\text { rejection }\end{array}$ & Yes & $\begin{array}{l}2,003,2,802,4,756, \\
5,872,6,990,19,018, \\
25,665 \mathrm{Da}\end{array}$ & $\begin{array}{l}\beta \text {-Defensin } 1, \\
\text { fragment of } \alpha_{1^{-}} \\
\text {antichymotrypsin }\end{array}$ & No & \\
\hline $\begin{array}{l}\text { Wittke } \\
\text { et al. [16] }\end{array}$ & CE-MS & $\begin{array}{l}\text { Allograft } \\
\text { rejection }\end{array}$ & Yes & $\begin{array}{l}16 \text { peptides ( } 5 \\
\text { upregulated): 1,168, } \\
1,707,2,078,2,121 \text {, } \\
3,359 \mathrm{Da}\end{array}$ & No & Yes & $\begin{array}{l}66 \% \text { correctly } \\
\text { classified as rejection }\end{array}$ \\
\hline $\begin{array}{l}\text { Jahnukainen } \\
\text { et al. [17] }\end{array}$ & $\begin{array}{l}\text { SELDI-TOF } \\
\text { MS }\end{array}$ & $\begin{array}{l}\text { Polyoma- } \\
\text { nephropathy }\end{array}$ & Partially & $\begin{array}{l}5,872,11,311,11,929 \\
12,727,13,349 \mathrm{Da}\end{array}$ & No & No & \\
\hline
\end{tabular}


sample handling, protocol for protein separation/visualization, and data analysis were not identical. This complicates direct comparison of these studies and highlights the need for some standardization in disease definition, preanalytical sample handling, and sample analysis.

Using SELDI-TOF MS, O'Riordan et al. [15, 26] found that decreasing levels of urinary $\beta$-defensin- 1 and increasing levels of a fragment of $\alpha_{1}$ antichymotrypsin were associated with renal allograft rejection. Although we identified a different protein as a potential biomarker for renal allograft rejection (i.e. cleaved $\beta_{2}$-microglobulin), in both studies fragments of a protein were predictive for the pathology. Low molecular weight fragments of a protein may simply be waste products that are even less informative than the intact protein form. However, they may also indicate increased protease activity associated with the allograft rejection process and may therefore provide important information. Clearly, the significance of protein fragments in the urine as biomarkers requires thorough investigation of the fragment, the intact protein, the responsible proteases and factors that activate them.

Protein identification of a potential biomarker is essential for several reasons. First, knowing the protein/peptide can help to understand their pathophysiology in the investigated process. Indeed, in our study we identified the previously detected potential biomarker for tubulointerstitial renal allograft rejection as cleaved $\beta_{2}$-microglobulin. As intact $\beta_{2}$-microglobulin is a wellknown biomarker for tubular injury, it became obvious that cleaved $\beta_{2^{-}}$ microglobulin was unlikely to be specific for rejection but rather an indicator of tubular injury [27]. O'Riordan et al. [26] identified $\beta$-defensin- 1 and a fragment of $\alpha_{1}$-antichymotrypsin as their previously detected biomarkers for renal allograft rejection, which are both involved in inflammatory processes. The other three groups have not yet identified their potential biomarkers (table 1) $[13,16,17]$. The second important reason for protein identification is that it allows one to select adequate control groups for a subsequent validation study and to identify major confounding factors (e.g. urine $\mathrm{pH}$, urine cell components, high proteinuria).

As already discussed above, validation in an independent sample set is the next critical step after detection of a potential biomarker. So far, only two of the five groups have performed a validation study. Wittke et al. [16] used CE-MS to analyze urines regarding peptide pattern associated with renal allograft rejection. In a small validation set, they could correctly classify $66 \%$ of samples as rejection. Our group used a validation sample set that was obtained in another center with refined control groups and side-by-side evaluation of comparable biomarkers. In fact, we could confirm the prevalence of cleaved $\beta_{2}$-microglobulin in patients with clinical tubulointerstitial rejection and stable transplants with normal tubular histology. However, the validation study revealed that cleaved 
$\beta_{2}$-microglobulin is (a) expectedly not specific for rejection, (b) unable to distinguish normal tubular histology from subclinical tubulointerstitial rejection, (c) similar to the other investigated biomarkers for tubular injury (retinol-binding protein, neutrophil-gelatinase-associated lipocalin, and $\alpha_{1}$-microglobulin), and (d) confounded by urine $\mathrm{pH}$ restricting its clinical usefulness [25]. These two studies highlight that validation is a key element in biomarker development and that many identified potential biomarkers will not pass this step.

\section{Conclusions}

With the low rejection and high short-term allograft survival rates that have been achieved in renal transplantation, the focus will shift to improve long-term outcomes. A major goal will be to tailor immunosuppression to the individual needs of every patient at every time point to balance risk for rejection and overimmunosuppression. To achieve this, novel biomarkers are necessary to detect subtle forms of allograft rejection and allograft injury, and to allow adapting immunosuppression before irreversible damage to the allograft has occurred.

Unbiased proteomics-based approaches raise the hope to reveal molecular mechanisms of allograft rejection and injury, which could translate into novel biomarkers. So far, no biomarker identified by an unbiased proteomics-based approach has found a clinical application. As detailed above, the currently published approaches were restricted to analysis of urine using high-throughput technology (i.e. CE-MS, SELDI-TOF MS), which can only assess a limited part of the proteome. The fast and continuous developments in the field of proteomics including more sensitive mass spectrometers with higher mass accuracy, differential protein expression technology (e.g. stable isotope labeling), and analysis of allograft tissue parts selected by laser-capture microdissection may allow gaining deeper insights into changes of the proteome associated with renal allograft rejection and/or injury. Eventually, these data may also reveal potential targets for future drug development.

\section{References}

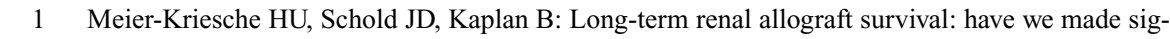
nificant progress or is it time to rethink our analytic and therapeutic strategies? Am J Transplant 2004;4:1289-1295.

$>2$ Meier-Kriesche HU, Schold JD, Srinivas TR, Kaplan B: Lack of improvement in renal allograft survival despite a marked decrease in acute rejection rates over the most recent era. Am $\mathrm{J}$ Transplant 2004;4:378-383. 
3 Pascual M, Theruvath T, Kawai T, Tolkoff-Rubin N, Cosimi AB: Strategies to improve long-term outcomes after renal transplantation. N Engl J Med 2002;346:580-590.

-4 Nankivell BJ, Borrows RJ, Fung CL, O’Connell PJ, Allen RD, Chapman JR: The natural history of chronic allograft nephropathy. N Engl J Med 2003;349:2326-2333.

$\checkmark 5$ Rush D: Protocol transplant biopsies: an underutilized tool in kidney transplantation. Clin J Am Soc Nephrol 2006;1:138-143.

-6 Moreso F, Ibernon M, Goma M, Carrera M, Fulladosa X, Hueso M, et al: Subclinical rejection associated with chronic allograft nephropathy in protocol biopsies as a risk factor for late graft loss. Am J Transplant 2006;6:747-752.

7 Racusen LC, Colvin RB, Solez K, Mihatsch MJ, Halloran PF, Campbell PM, et al: Antibodymediated rejection criteria - an addition to the Banff 97 classification of renal allograft rejection. Am J Transplant 2003;3:708-714.

$>8$ Schaub S, Wilkins JA, Rush D, Nickerson P: Developing a tool for noninvasive monitoring of renal allografts. Expert Rev Proteomics 2006;3:497-509.

$\checkmark 9$ Hewitt SM, Dear J, Star RA: Discovery of protein biomarkers for renal diseases. J Am Soc Nephrol 2004;15:1677-1689.

10 Tirumalai RS, Chan KC, Prieto DA, Issaq HJ, Conrads TP, Veenstra TD: Characterization of the low molecular weight human serum proteome. Mol Cell Proteomics 2003;2:1096-1103.

11 Schaub S, Wilkins J, Weiler T, Sangster K, Rush D, Nickerson P: Urine protein profiling with surface-enhanced laser-desorption/ionization time-of-flight mass spectrometry. Kidney Int 2004;65: 323-332.

12 Donaldson MD, Chambers RE, Woolridge MW, Whicher JT: Stability of $\alpha 1$-microglobulin, $\beta 2$ microglobulin and retinol binding protein in urine. Clin Chim Acta 1989;179:73-77.

13 Clarke W, Silverman BC, Zhang Z, Chan DW, Klein AS, Molmenti EP: Characterization of renal allograft rejection by urinary proteomic analysis. Ann Surg 2003;237:660-665.

14 Schaub S, Rush D, Wilkins J, Gibson IW, Weiler T, Sangster K, et al: Proteomic-based detection of urine proteins associated with acute renal allograft rejection. J Am Soc Nephrol 2004;15:219-227.

15 O'Riordan E, Orlova TN, Mei JJ, Butt K, Chander PM, Rahman S, et al: Bioinformatic analysis of the urine proteome of acute allograft rejection. J Am Soc Nephrol 2004;15:3240-3248.

16 Wittke S, Haubitz M, Walden M, Rohde F, Schwarz A, Mengel M, et al: Detection of acute tubulointerstitial rejection by proteomic analysis of urinary samples in renal transplant recipients. Am J Transplant 2005;5:2479-2488.

17 Jahnukainen T, Malehorn D, Sun M, Lyons-Weiler J, Bigbee W, Gupta G, et al: Proteomic analysis of urine in kidney transplant patients with BK virus nephropathy. J Am Soc Nephrol 2006;17: 3248-3256.

18 Sorof JM, Vartanian RK, Olson JL, Tomlanovich SJ, Vincenti FG, Amend WJ: Histopathological concordance of paired renal allograft biopsy cores. Effect on the diagnosis and management of acute rejection. Transplantation 1995;60:1215-1219.

19 Nicholson ML, Wheatley TJ, Doughman TM, White SA, Morgan JD, Veitch PS, et al: A prospective randomized trial of three different sizes of core-cutting needle for renal transplant biopsy. Kidney Int 2000;58:390-395.

20 Baggerman G, Vierstraete E, De Loof A, Schoofs L: Gel-based versus gel-free proteomics: a review. Comb Chem High Throughput Screen 2005;8:669-677.

21 Steel LF, Haab BB, Hanash SM: Methods of comparative proteomic profiling for disease diagnostics. J Chromatogr B Analyt Technol Biomed Life Sci 2005;815:275-284.

22 Schaub S, Wilkins JA, Antonovici M, Krokhin O, Weiler T, Rush D, et al: Proteomic-Based Identification of Cleaved Urinary $\beta 2$-microglobulin as a Potential Marker for Acute Tubular Injury in Renal Allografts. Am J Transplant 2005;5:729-738.

23 Zolg W: The proteomic search for diagnostic biomarkers: lost in translation? Mol Cell Proteomics 2006;5:1720-1726.

24 Diamandis EP: Mass spectrometry as a diagnostic and a cancer biomarker discovery tool: opportunities and potential limitations. Mol Cell Proteomics 2004;3:367-378.

25 Schaub S, Mayr M, Hönger G, Bestland J, Steiger J, Regeniter A, et al: Detection of Subclinical Tubular Injury after Renal Transplantation: Comparison of Urine Protein Analysis with Allograft Histopathology. Transplantation 2007; in press. 
26 O'Riordan E, Orlova TN, Podust VN, Chander PN, Yanagi S, Nakazato M, et al: Characterization of urinary Peptide biomarkers of acute rejection in renal allografts. Am J Transplant 2007;7: 930-940.

27 Schardijn GH, Statius van Eps LW: $\beta 2$-microglobulin: its significance in the evaluation of renal function. Kidney Int 1987;32:635-641.

Stefan Schaub, MD, MSc

Department for Transplantation Immunology and Nephrology, University Hospital Basel

Petersgraben 4

CH-4031 Basel (Switzerland)

Tel. +41 61265 4533, Fax +4161265 2410, E-Mail schaubs@uhbs.ch 